\title{
Erratum
}

Biogeochemistry 69: 263-284, 2004.

(C) 2004 Kluwer Academic Publishers. Printed in the Netherlands.

\section{Photodegradation of DOC in a shallow prairie wetland: evidence from seasonal changes in DOC optical properties and chemical characteristics}

\author{
MARLEY J. WAISER and RICHARD D. ROBARTS
}

Due to an unfortunate technical error, during printing there occurred numerous errors in the spelling of the aforementioned article. This did not affect the scientific content of the article, but is unacceptable nontheless. Springer would like to offer its sincerest apologies to the authors for this mishap. The article is hereby reprinted in full. 


\title{
Photodegradation of DOC in a shallow prairie wetland: evidence from seasonal changes in DOC optical properties and chemical characteristics
}

\author{
MARLEY J. WAISER* and RICHARD D. ROBARTS \\ National Water Research Institute, 11 Innovation Blvd., Saskatoon, SK, Canada; *Author for \\ correspondence (e-mail: marley.waiser@ec.gc.ca; phone: +1-306-975-5762; fax: +1-306-975-5143)
}

Received 20 June 2003; accepted in revised form 21 August 2003

Key words: ${ }^{13} \mathrm{C}$ NMR, DOC, DOC molecular weight and size, Photodegradation, Prairie wetlands, Spectral slope, Water optical properties

\begin{abstract}
Wetlands across the Canadian prairies are typically shallow $(<1.0 \mathrm{~m})$ and exhibit high dissolved organic carbon (DOC) concentrations $\left(>10 \mathrm{mgl}^{-1}\right)$. Studies have shown that DOC in such shallow wetlands is not as reliable an indicator of ultraviolet radiation (UVR) attenuation as it is in clearwater. Changes in DOC character and composition as a result of sunlight exposure might provide a reasonable explanation for this observation. To test this, we investigated seasonal changes in DOC optical and chemical properties in a shallow prairie wetland over a 2-year period. Although DOC concentration increased at least two-fold from spring until fall, DOC specific absorption (at $350 \mathrm{~nm}$ ) and fluorescence decreased by 30 and $32 \%$, respectively, for the same period. In both years, seasonal decreases in DOC molecular weight and size (from measurements of tangential filtration and mass electrospray mass spectrometry) were reflected in concomitant increases in spectral slope. ${ }^{13} \mathrm{C}$ NMR analysis of DOC isolated on XAD-8 resins revealed a $49 \%$ decrease in aromatic moieties when spring values were compared to those in the fall. As well, $\delta^{13} \mathrm{C}$ signatures of this isolated DOC became heavier seasonally. In a short term photodegradation experiment (6 days) we noted a $47 \%$ decline in DOC specific absorption coefficients at $350 \mathrm{~nm}$ and a $15 \%$ increase in spectral slope when water exposed to the total light spectrum was compared to that of a dark control. Taken together, all of these observations were consistent with the occurrence of seasonal DOC photodegradation in shallow prairie wetlands and underlined the importance of this process in shaping DOC character and composition in these hydrologically dynamic systems. Our data also indicates that constant mixing and shallow depths in these wetlands were factors which enhanced DOC photodegradation. Although the high DOC concentrations of prairie wetlands should theoretically offer protection for their biota, seasonal photodegradation of DOC means that these systems may not be as protected as their high DOC concentrations suggest.
\end{abstract}

\section{Introduction}

Dissolved organic carbon (DOC) participates in many biogeochemical reactions in lakes and presumably in wetlands. It flocculates chemical substances, adsorbs pesticides, and 'fuels' microbial food webs (Schiff et al. 1990; Schindler and Curtis 1997). The ability of DOC to attenuate photosynthetically active (PAR) and ultraviolet radiation (UVR) not only restricts the depth of autotrophic production in aquatic ecosystems but also protects aquatic organisms from harmful UVR (Schindler and Curtis 1997). But a portion of DOC is also highly photoreactive. It takes part in a number of photochemical reactions that produce not only harmful oxidants such as peroxide, but low molecular weight carbon compounds suitable for bacterial uptake (Lindell et al. 
1995; Scully et al. 1995). The interaction between DOC and solar radiation can result in a loss of colour (photobleaching), presumably due to the breakdown of aromatic constituents (Moran et al. 2000; Waiser and Robarts 2000). Such colour loss has been linked to increased penetration of damaging UVR (Morris and Hargreaves 1997).

Lakes and wetlands across the Canadian prairies typically have DOC concentrations $>10 \mathrm{mg} \mathrm{l}^{-1}$ and sometimes $>100 \mathrm{mg} \mathrm{l}^{-1}$ (Curtis and Adams 1995; Arts et al. 2000); as a result, the water may be highly coloured. To date, most research into DOC in the prairie region has focused on saline ecosystems. For example, DOC concentration increases with increasing salinity (Curtis and Adams 1995). As well, the location of these saline systems within hydrologically closed basins contributes not only to photodegradation of DOC, but increased UVR penetration (Waiser and Robarts 2000). Consequently, they have remarkably different optical properties than their freshwater counterparts (Arts et al. 2000). But in prairie wetlands, virtually nothing is known regarding either DOC concentrations or the impact of photodegradation on DOC optical properties or chemical characteristics. These systems are of interest for a number of reasons. First, they number in the millions and are ecologically important - supporting 50-80\% of the North American duck population in any given year (Batt et al. 1989). Secondly, they contain high concentrations of DOC which, according to current models, should offer considerable protection from harmful ultraviolet radiation, but which also could be quite photoreactive. Thirdly, wetlands are shallow, hydrologically dynamic systems. Although water levels are recharged in spring from snow meltwater runoff, high evaporative stress in this semi-arid climatic zone means that many wetlands lose considerable water volume and depth during the ice-free season. Finally, like saline lakes, most prairie wetlands occur in hydrologically closed basins. Morris and Hargreaves (1997) pointed out that aquatic ecosystems of depths $<10 \mathrm{~m}$ might be extremely susceptible to UVR effects. Taken together, this information suggests that DOC in prairie wetlands might undergo considerable changes in composition and character seasonally. If this was true, these wetlands might not be as protected from harmful UVR as their high DOC concentrations would suggest.

Penetration of UVR is a function of DOC concentration, composition and optical properties, all of which vary on seasonal time scales (Morris and Hargreaves 1997; Laurion et al. 2000; Osburn et al. 2001). The first goal of this study, therefore, was to investigate seasonal changes in DOC concentration, composition and optical properties in a shallow prairie wetland over a 2-year period. A combination of techniques, including measurements of DOC absorbance, absorption coefficients, fluorescence, molecular size (tangential filtration), and spectral slope on whole water samples were employed to accomplish this objective. The second goal was to try and relate changes in water optical properties to actual chemical changes in DOC. To do this, the hydrophobic acid fraction of DOC was isolated on XAD-8 resins and then characterized using ${ }^{13} \mathrm{C}$ NMR analyses and $\delta^{13} \mathrm{C}$ signatures. Mass electrospray mass spectrometry (on isolated DOC) was used to corroborate other measures of molecular size. A short-term photodegradation experiment (6 days) was also conducted to determine if seasonal changes in DOC composition and character observed in situ could be related to sunlight exposure. It was expected 
that these methods would allow insights into the interaction between sunlight and DOC composition and optical properties in prairie wetlands. In so doing, we would also be able to draw some conclusions regarding the extent to which these ecologically important water bodies might be protected by their high DOC concentrations.

\section{Materials and methods}

Study site

The St. Denis National Wildlife Area, $40 \mathrm{~km}$ east of Saskatoon, Saskatchewan, Canada $\left(106^{\circ} 06^{\prime} \mathrm{W}, 52^{\circ} 02^{\prime} \mathrm{N}\right.$ ) (Woo and Rowsell 1993) is located within the mixed-grass prairie-parkland ecotone, covering 385 ha in the rolling morainic topography of the Minichinas Hills. There are more than 100 wetlands within this area, ranging from ephemeral to permanent and freshwater to saline. One wetland at the St. Denis Wildlife Refuge was chosen as the research site for this study. Pond $50,31,000 \mathrm{~m}^{2}$ in area, is a centrally drained, semi-permanent wetland surrounded by marsh. The lowest point of the basin is $547 \mathrm{~m}$ above sea level while the maximum elevation is $566 \mathrm{~m}$ (Su et al. 2000). Water levels fluctuate widely on a yearly basis, and although filled with water most years, the pond may completely disappear depending on spring water inputs from snowmelt and runoff (Woo and Rowsell 1993). Mean annual precipitation in this area is $353 \mathrm{~mm}, 27 \%$ of which falls as snow (Woo and Rowsell 1993). In the semi-arid prairie pothole region, evaporation exceeds precipitation - the 90-year mean annual precipitation for Saskatoon is $360 \mathrm{~mm}$ while evaporation averages $690-710 \mathrm{~mm}$ (Hayashi 1996). Evaporation can be considerable in this wetland region, especially since most ponds have no outflow. In fact, evaporation accounts for $>80 \%$ of the water loss in Pond 50 (Woo and Rowsell 1993). Pond 50 is alkaline (mean pH $8.7 \pm 0.5 \mathrm{SD} ; n=62$ ), slightly saline (TDS $4.0 \mathrm{gl}^{-1}$ - mean value from 1993-1996; $n=37$ ) with magnesium (49\%) and sulfate (94\%) the dominant ions. Seasonal mean value for chlorophyll $a(\mathrm{Chl} a)$ in this pond is $8.2 \mu \mathrm{gl}^{-1}(n=62$; Waiser 2001).

\section{Pond temperature and depth}

In 2000, 3 Onset Optic Stowaway temperature loggers (temperature range -4 to $+37^{\circ} \mathrm{C}$ - Hoskins Scientific) were placed in Pond 50 to monitor temperature at various depths throughout the ice-free season. Loggers were mounted on a stake driven into the sediments near the centre of the pond. Pond depth at this location was approximately $25 \mathrm{~cm}$ and loggers were positioned just under the surface and then at 10 and $20 \mathrm{~cm}$ (surface, middle and just above the bottom of the pond). Temperature data was logged at half hour intervals and subsequently dumped to a computer. This data was collected to establish if this pond stratified during the ice-free season. Pond depth was measured periodically each year at a centrally located stake. 


\section{Dissolved organic carbon}

\section{Concentration}

From 1999 to 2000, water samples were collected fortnightly from May through until October. Samples were screened through $153 \mu \mathrm{m}$ mesh size Nitex netting, filtered through combusted GF/C filters (Whatman) and then analysed for DOC using UV oxidation followed by infrared detection (Environment Canada 1992). DOC values using this method are highly correlated with those obtained using high temperature combustion (Lean 1998).

\section{Characterization of whole water samples}

\section{Tangential filtration}

A Centramate (Pall Corporation, Long Island, NY) 1000 Dalton (D) cutoff polyethersulfone tangential filter was used to establish the percentage of DOC $<1000$ in 1999. Screened pond water was collected monthly, filtered through combusted GF/ C filters (nominal pore size $1.2 \mu \mathrm{m}$ ) and some analysed for DOC. Approximately $300 \mathrm{ml}$ of this water was then pumped through the tangential unit and collected for DOC analysis. Knowing DOC concentrations in both the $\mathrm{GF} / \mathrm{C}$ and tangential filtrate allowed calculation of the percentage of total DOC $<1000 \mathrm{D}$.

\section{Absorbance scans}

Approximately every 2 weeks, water was collected, screened, and filtered though combusted GF/F filters (Whatman; nominal pore size $0.7 \mu \mathrm{m}$ ). Filtered water was placed in $1 \mathrm{~cm}$ quartz cuvettes and absorbance measured at $2 \mathrm{~nm}$ intervals from 200 to $700 \mathrm{~nm}$ using a Shimadzu scanning UV-VIS spectrophotometer (Model UV1601PC). To compare seasonal data, absorbance values were normalized to DOC concentrations due to the large seasonal DOC increase.

Absorption coefficients at $350 \mathrm{~nm}\left(\mathrm{a}_{350}\right)$

Absorbance values at $350 \mathrm{~nm}$ were converted to absorption coefficients according to the equation

$$
a_{\lambda}=\frac{A_{\lambda} 2.303}{1} \quad(\text { Miller 1998) }
$$

where $a_{\lambda}$ is equal to the absorption at $\lambda, A_{\lambda}$ is the absorbance at $\lambda$ and $l$ is the pathlength of the cuvette in $\mathrm{m}$. Absorption coefficients at $350 \mathrm{~nm}$ were taken as an index of coloured dissolved organic matter (CDOM - Moran et al. 2000). These coefficients were normalized to DOC concentrations (DOC specific absorption) to ascertain seasonal changes in the optical characteristics of CDOM.

Spectral slope (S)

The $S$ value is a measure of the rate at which absorptivity decreases at longer wavelengths (Miller 1998) and was used in this study to track seasonal changes in 
DOM optical properties and molecular size (Vodacek et al. 1997; Markager and Vincent 2000). Absorption coefficients were calculated from absorbance values (see above). Absorption coefficient data was then linearized using natural log transformations and $S$ estimated from a least-squares regression of the natural log of the absorption coefficient versus wavelength (Morris and Hargreaves 1997; Moran et al. 2000). Slopes were calculated over the wavelength range $290-420 \mathrm{~nm}$ (Moran et al. 2000).

\section{DOC fluorescence}

In 1999, water samples were collected every 2 weeks and filtered through combusted GF/F filters for subsequent DOC and DOC fluorescence analysis. DOC fluorescence was measured in quartz cuvettes using a Shimadzu RF-1501 scanning spectrofluorometer with a Xenon lamp and a concave non-aberration excitation/emission monochromator according to the method of Donahue et al. (1998). Scans of sample blanks were performed using distilled, deionized water in order to remove effects of Raman scattering. Absolute fluorescence values are reported in quinine sulfate units (QSU) where $1 \mathrm{QSU}$ is equivalent to the fluorescence of a $1 \mu \mathrm{gl}^{-1}$ quinine sulfate solution in $0.1 \mathrm{~N} \mathrm{H}_{2} \mathrm{SO}_{4}$. Excitation wavelength was fixed at $370 \mathrm{~nm}$, and scans of emission intensities performed from 370 to $650 \mathrm{~nm}$. Peak fluorescence was established from emission scans, blank corrected and subsequently normalized to DOC concentration as above (DOC specific fluorescence).

Fractionation of hydrophobic acids on XAD-8 resins and subsequent characterization

In 1999, water samples were collected monthly at the open water site (May to September) in clean 201 carboys. At the lab, water was tangentially filtered using a Centramate (Pall Corporation, Long Island, NY) filtering system equipped with 20.0 and $1.0 \mu \mathrm{m}$ pore-size pre-filters and a $0.1 \mu \mathrm{m}$ polyethersulfone cartridge. The filtrate was acidified to $\mathrm{pH} 2$ with $1 \mathrm{~N} \mathrm{HCl}$ and then passed through a column containing XAD-8 ion exchange resin (Thurman and Malcolm 1981). After the entire water sample had passed through, the column was rinsed with Milli-Q water until neutral $\mathrm{pH}$ was achieved. Subsequent backflushing with $0.1 \mathrm{~N} \mathrm{NaOH}$ removed the hydrophobic acid fraction (HPOA). This highly coloured effluent was collected in clean $11 \mathrm{Nalgene}$ bottles, frozen at $-40^{\circ} \mathrm{C}$, and then freeze-dried to powder.

\section{Characterization of freeze-dried hydrophobic acids}

$\delta^{13} C$ analysis

Some of the freeze-dried DOC sample was analysed for $\delta^{13} \mathrm{C}$. Samples were combusted at $850^{\circ} \mathrm{C}$ using the Dumas technique and the resulting $\mathrm{CO}_{2}$ trapped and purified cryogenically for subsequent $\delta^{13} \mathrm{C}$ analysis (McGaw et al. 1988). 
Analyses for $\delta^{13} \mathrm{C}$ were done on a Fisons VG Optima Isotope Ratio Mass and reported using the $\delta$ notation relative to the international Pee Dee Belemnite (PDB) standard where

$$
\delta^{13} \mathrm{C}=\left(\frac{R_{\text {sample }}}{R_{\text {standard }}}-1\right) 1000
$$

and $R$ is the ${ }^{13} \mathrm{C} /{ }^{12} \mathrm{C}$ ratio in the sample or the standard.

\section{${ }^{13} C$-NMR spectroscopy}

Freeze-dried DOC samples from May and September were also analysed using ${ }^{13} \mathrm{C}$ NMR spectroscopy according to the method of McKnight et al. (1991). This method produces well-resolved, chemically informative, semi-quantitative spectra from which the percentage of carbon atoms in various functional groups can be estimated (Clair and Sayer 1997). Solid state NMR spectra were divided into specific chemical shift regions according to organic carbon functional groups present in the freeze-dried sample. The region between 0 and $60 \mathrm{ppm}$ (AL-I) represents aliphatic carbons and includes both lipids and fatty acids. Carbohydrates dominate the region between 60 and $110 \mathrm{ppm}$ and consist of two fractions; AL-II (60-90) and AL-III (90-110). The region between 110-160 ppm is representative of aromatic carbon (AR), including the phenolic region between 140 and $160 \mathrm{ppm}$. Carboxylic carbon (C-I) dominates the region from 160 to 190 while carbonyl signals (C-II - ketones and aldehydes) are present in the region from 190 to $210 \mathrm{ppm}$ (McKnight et al. 1994). The spring and fall dates were chosen as representative end-members, that is, if photodegradation of DOC had occurred, samples in which the greatest change in carbon constituents would be expected.

Mass electrospray/Mass spectrometry

To determine the average molecular weight of the constituents, some of the freeze dried eluant was analysed by mass electrospray mass spectrometry in the negative ion mode using an Autospec Q mass spectrometer (Micromass, UK). Mass spectrometer settings were as follows: source temperature at $80^{\circ} \mathrm{C}$, cone voltage setting at $23 \mathrm{~V}$, needle voltage setting at $56.2 \mathrm{~V}$, and a flow rate of $\mathrm{N}_{2}$ nebulizer and bath gas set at 15 and $200 \mathrm{lh}^{-1}$, respectively. The resolution was tuned to 1200 and the detector set to $415 \mathrm{~V}$. Qualitative analysis was performed using the full scan data $(100-800 \mathrm{~m} / \mathrm{z})$. A Phoenix 20 (Fisons) syringe pump was employed for eluant delivery at a flow rate of $200 \mu \mathrm{min}^{-1}$ with a post column split allowing $30 \mu \mathrm{min}^{-1}$ to the ES source. Eluant consisted of 50:50 acetonitrile:water plus $0.5 \%$ ammonium hydroxide. Loop injection was performed using a Reodyne 7125 injector. Electrospray is a soft ionization technique which theoretically causes little fragmentation of sample (Voyksner 1994).

Photochemical degradation experiment

In July 2000, water was collected from the middle of the pond, screened (as above) and placed in clean, 201 Nalgene carboys. At the lab, water was tangentially filtered 
using the Centramate system (see above). Filtrate was collected and some analysed for DOC. Absorbance scans were also run on this water (see above). The remaining filtered water was placed in fifteen, $300 \mathrm{ml}$ clean polystyrene culture bottles (pathlength $3 \mathrm{~cm}$ ). Five bottles were wrapped in aluminium foil (dark control) and all flasks placed (flat side exposed to sunlight) on racks in a large flow through water bath on the roof of the National Hydrology Research Center. A sheet of Acrylite OP3 was subsequently placed over five of the bottles (PAR) while another five remained coverless (PAR + UV-A + UV-B). Water was exposed to sunlight for a period of 6 days. This exposure period was deemed suitable based on the hydrologically closed nature of the pond (no inflow or outflow).

An Optronics scanning spectroradiometer (Model OL-754) equipped with a cosine receptor (Optronics Laboratories Inc., Model OL IS-670) was used to monitor incident radiation during the experiment. To determine transmission characteristics, pieces were cut from the polystyrene flasks and acrylite, placed over the spectroradiometer light sensor and scans run from 200 to $700 \mathrm{~nm}$.

At experiment end, water samples were collected from one of each light treatment for DOC analysis. Water was also collected from each bottle and absorbance scans run as outlined above. In addition, absorption coefficients at $350 \mathrm{~nm}$ were calculated (as above) to give an indication of changes in absorbance characteristics of CDOM. Spectral slopes were also calculated (as above) and compared. A one-way ANOVA (Sigmastat) with a post hoc Tukey's test was used to test to test for differences among treatments. The significance level for testing was $p<0.05$.

\section{Results}

Pond temperature and depth

Pond temperatures were isothermal from top to bottom and stratification never occurred. Only representative data from May is shown (Figure 1(A)).

Pond depth in 1999 declined from $71.5 \mathrm{~cm}$ in early May to $56 \mathrm{~cm}$ in mid-October. In 2000, the variation over the same time period was from 58 to $22.5 \mathrm{~cm}$ (Figure 1(B))

\section{DOC concentration}

In 1999, DOC concentration in Pond 50 increased from $35.2 \mathrm{mg}^{-1}$ in May to a maximum of $67.8 \mathrm{mgl}^{-1}$ in mid-October - mean $=54 \mathrm{mgl}^{-1}( \pm 9.1 \mathrm{SD} ; n=11)$ (Figure 2(A)). In 2000, DOC in early May was $40.8 \mathrm{mg} \mathrm{l}^{-1}$ and reached $120 \mathrm{mgl}^{-1}$ at the end of September (Figure 2(A)). Mean DOC concentration was $71.9 \mathrm{mg}^{-1}$ $( \pm 24.3 \mathrm{SD} ; n=11)$. In both years, seasonal increases in DOC concentration were linear with time $\left(1999, r^{2}=0.96 ; 2000, r^{2}=0.90\right.$ - Figure 2(A)) and were highly correlated with chloride ion concentration $\left(1999, r^{2}=0.95 ; 2000, r^{2}=0.99\right.$ - Waiser 2001). The strong relationship between DOC and chloride suggests that DOC in this pond evapoconcentrates over time. 

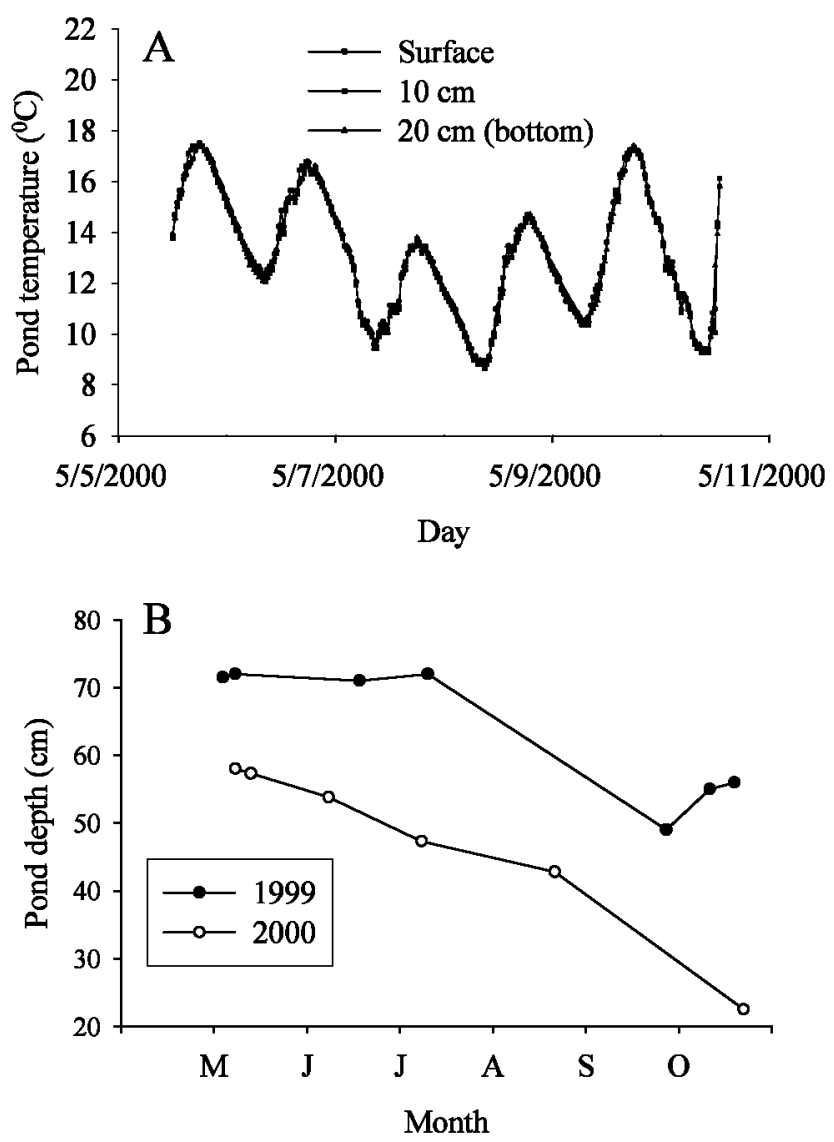

Figure 1. Daily temperature variation at three depths in Pond 50, early May 1999 (A) and seasonal variation pond depth (B) at Pond 50 in 1999 (closed circles) and 2000 (open circles).

\section{Tangential filtration}

In 1999, the percent DOC $<1000 \mathrm{D}$ was 17.7 in early May. By 17 June however, this percentage had risen to $57.6 \%$, reaching a maximum of $64.9 \%$ in early September (Figure 2(B)).

\section{DOC absorbance}

Absorbance of DOC in Pond 50 increased seasonally in both 1999 and 2000 (data not shown). When this data was normalized to DOC concentration, however, there was actually a clear seasonal loss of absorbance per mg DOC (Figure 2(C) only 1999 data shown). While most of this loss occurred within the UV range 

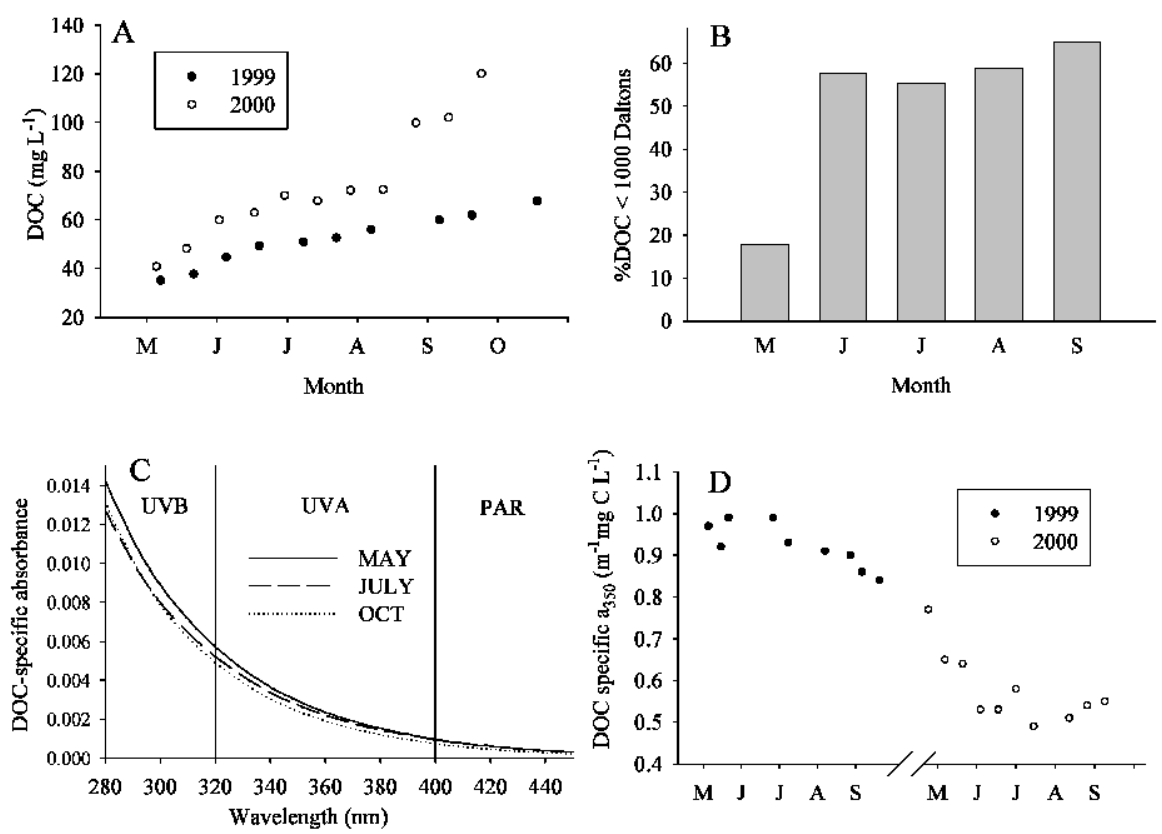

Figure 2. Seasonal variation in DOC concentration in 1999 and 2000 (A) and percentage of DOC $<1000$ D in 1999 (B) in Pond 50 as well as changes in DOC specific absorbance from May, July and October, 1999 (C) and seasonal variation in DOC specific absorptivity ( $\left.\mathrm{m}^{-1} \mathrm{mg} \mathrm{Cl}^{-1}-1999-2000\right)$ (D).

(280-400 nm), some was evident within the visible ( $>400 \mathrm{~nm})$. In 2000, most of the absorbance loss occurred prior to the end of July, while in 1999 absorbance continued to decline into October (data not shown).

Absorption coefficients at $350 \mathrm{~nm}\left(\mathrm{a}_{350}\right)$

Although DOC concentrations increased dramatically on a seasonal basis in both years, DOC specific $a_{350}$ decreased (Figure 2(D)). In 1999, there was a gradual seasonal decline in DOC specific $a_{350}$ with October values $29 \%$ less than those in May (Figure 2(D)). In 2000, however, the majority of absorbance was lost between May and the end of July (36.4\%). After the end of July $a_{350}$ values increased slightly so that by the end of September, the loss was only $29.4 \%$ of May values (Figure 2(D)). This gain was probably due to large increases in DOC concentration $-47.9 \mathrm{mg} \mathrm{l}^{-1}$ from 23 July to 20 September.

Spectral slope (S)

In 1999, $S$ averaged $0.020 \mathrm{~nm}^{-1}( \pm 0.0007 \mathrm{SD} ; n=9)$ while in 2000 the average was slightly higher $-0.023 \mathrm{~nm}^{-1}( \pm 0.0008 \mathrm{SD} ; n=11)$. In both years, $S$ increased from 

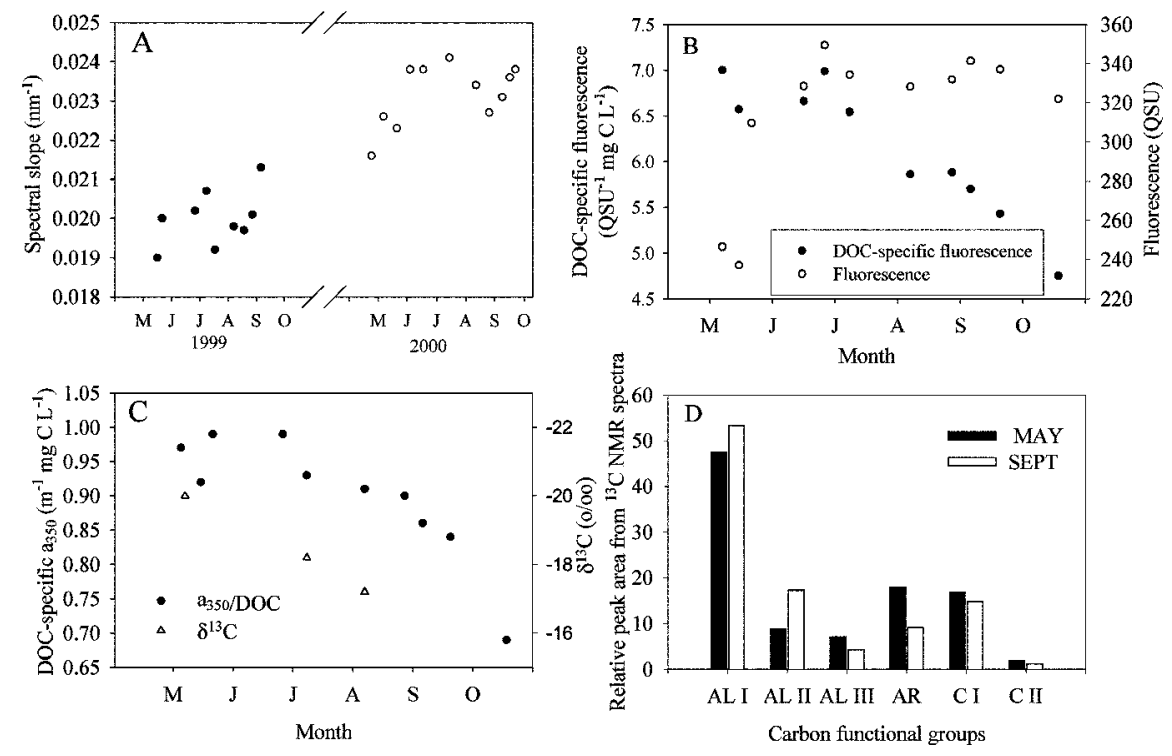

Figure 3. Seasonal variation in spectral slope (1999-2000) (A), and fluorescence of whole water samples (B) (1999) as well as variation in $\delta^{13} \mathrm{C}$ of XAD-8 isolated DOC (1999). (D) Illustrates changes in relative peak areas from ${ }^{13} \mathrm{C}$ NMR analyses of isolated DOC from May and September 1999.

spring through fall - in 1999 September values had increased 6\% over those in spring, while in 2000 this increase had doubled to $12 \%$ (Figure 3(A)). The increase was not linear over time.

\section{DOC fluorescence}

Peak fluorescence of DOC in Pond 50 occurred at $424 \mathrm{~nm}$. In 1999, DOC fluorescence increased dramatically from May until early July (Figure 3(B)) perhaps because DOC concentration increased by $14 \mathrm{mgl}^{-1}$ in this 2 -month time frame (Figure 2(A)). Although DOC concentrations increased by $18 \mathrm{mg}^{-1}$ from the end of June until mid-October, there was very little change in fluorescence (Figure 3(B)). DOC specific fluorescence data, however, indicated that the amount of fluorescence per $\mathrm{mg}$ of DOC in October had actually declined $32 \%$ from initial May values (Figure 3(B)).

\section{Characteristics of freeze dried hydrophobic acids}

\section{$\delta^{13} \mathrm{C}$ analysis}

The average $\delta^{13} \mathrm{C}$ signature of hydrophobic organic acids was $19.5 \%$ \% $( \pm 2.4 \mathrm{SD} ; n=3)$. Values in August were heavier (-17.2\%) than those in May (-20.0\% - Figure 3(C)). 


\section{A}

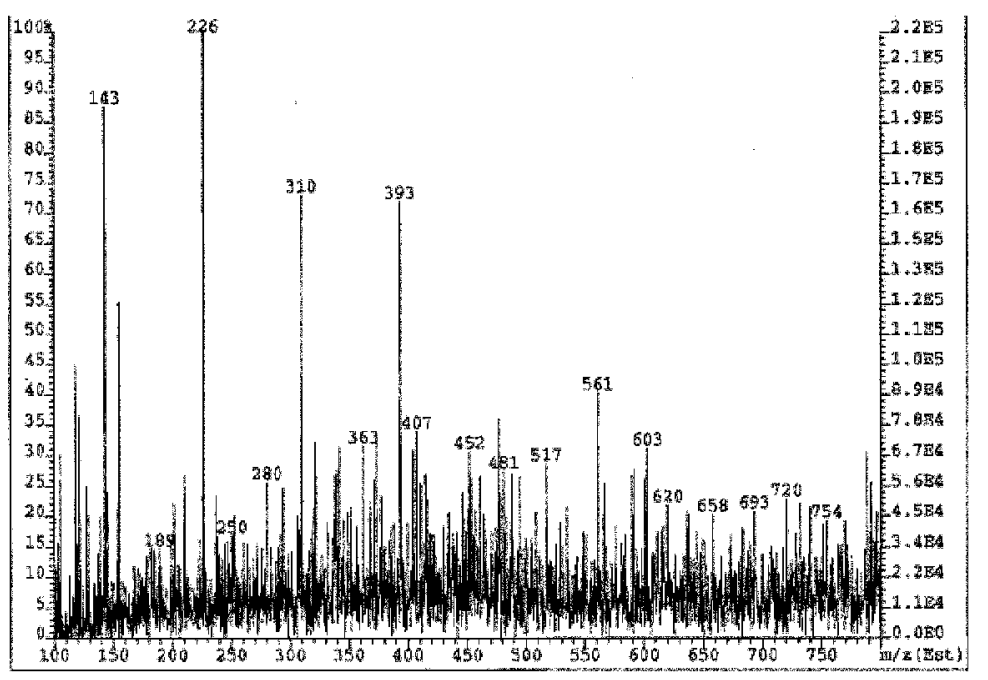

Atomic Mass (Daltons)

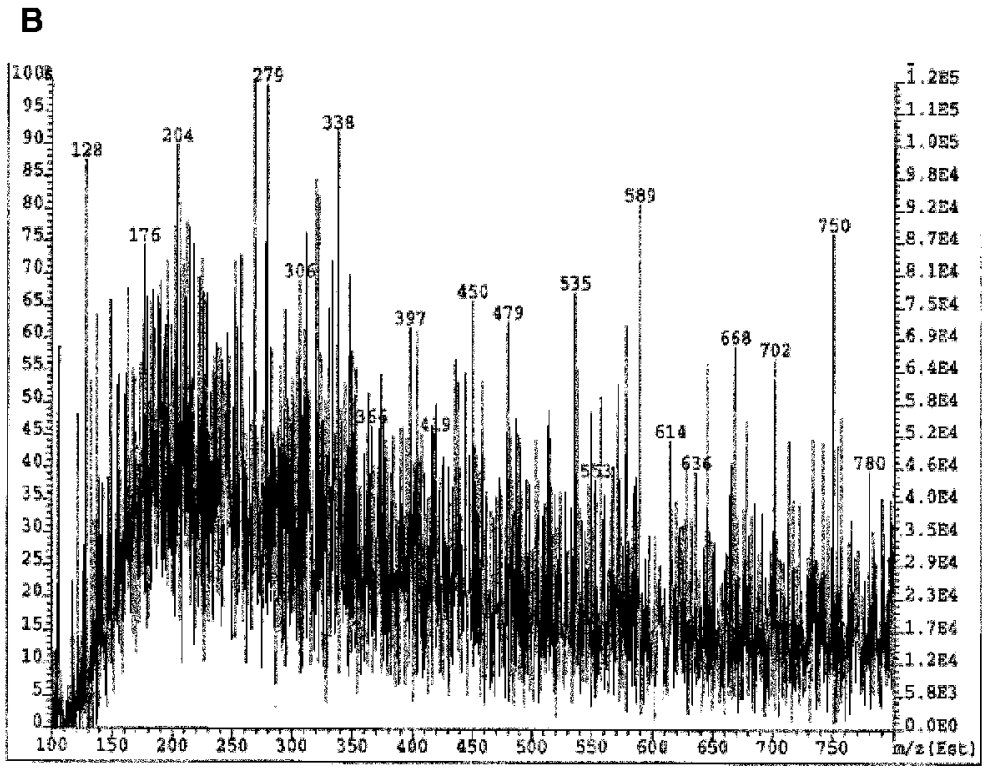

Atomic Mass (Daltons)

Figure 4. Mass electrospray mass spectrograms of DOC isolated from Pond 50 in May (A) and September (B) 1999. 

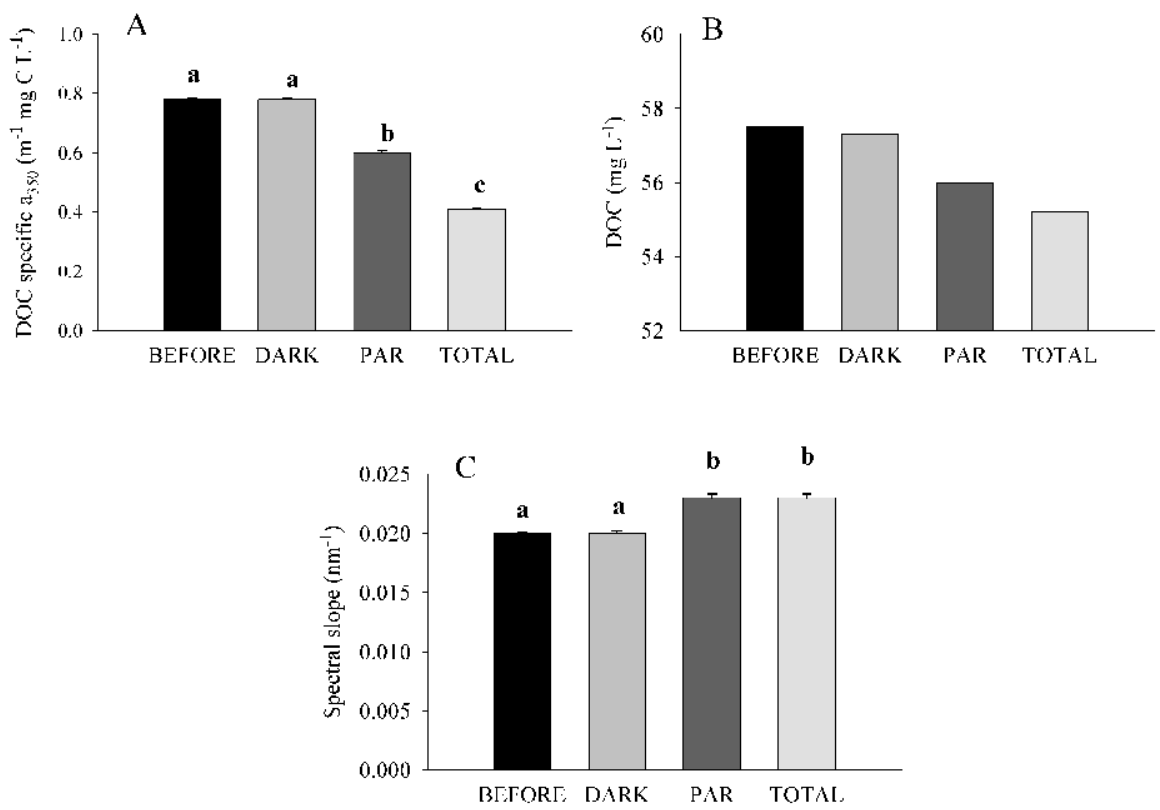

Figure 5. Results from the photodegradation experiment conducted in July 2000 showing changes in DOC specific absorption coefficients $(350 \mathrm{~nm})(\mathrm{A})$, DOC concentration (B) and spectral slope (C) in water samples exposed to sunlight compared to those held in the dark. Error bars indicate standard deviation $(\mathrm{n}=5)$. Treatments with different letters were statistically different at the end of the experiment $(\mathrm{p}<0.05$, ANOVA).

\section{${ }^{13}$ C NMR}

According to the ${ }^{13} \mathrm{C}$ NMR analyses, percent aromaticity in isolated DOC in May was $17.9 \%$, but by September had decreased to 9.1 - a decline of $49 \%$ (Figure 3(D)). In the CI and CII regions, representative of carboxylic and carbonyl compounds, relative percentages declined, compared to May values by 12 and 37\%, respectively (Figure 3(D)). At the same time, the relative percentage of total aliphatics (AL-I + AL-II + AL-III) increased by $18 \%$.

Mass spectrometry/mass electrospray analyses

Mass electrospray spectrograms showed a heterogeneous assortment of carbon compounds of differing molecular weights. Although the May sample showed no trend in molecular weights (Figure 4(A)), a definitive molecular weight envelope (peak) was present by September (Figure 4(B)). This peak was centred between 200 and $250 \mathrm{D}$.

Photochemical degradation of dissolved absorbance and DOC

Incident PAR, UV-A and UV-B irradiance measurements averaged 278, 34 and $1.4 \mathrm{~W} \mathrm{~m}^{-2}$, respectively during the experiment. Scans run on plexiglas (Acrylite OP-3) indicated that no UV-B, $0.1 \%$ UV-A, and $90.9 \%$ of PAR light were 
transmitted. Scans done with polystyrene showed that this filter transmitted $44 \%$ of UV-B, $76 \%$ of UV-A and $92.1 \%$ of PAR.

Absorbance data indicated significant photobleaching of DOC during the exposure period. DOC specific $a_{350}$ values for PAR and TOTAL light treatments declined by 23 and $47 \%$ compared to dark treatments (Figure 5(A)). Differences were significant except between the before and dark treatments. DOC concentrations in the exposed treatments were less than in the 'before' exposure or dark treatments but analyses were not replicated so statistical tests could not be performed to elucidate significant differences (Figure 5(B)). Polystyrene, however, may depolymerize to styrene when exposed to sunlight. In experiments such as ours, where water is held in sunlight irradiated polystyrene containers, such a process could cause an increase in DOC concentration (Vähätalo et al. 1998). DOC concentrations in solar irradiated flasks, therefore, would reflect photodegradation of DOC and polystyrene. Using this reasoning then, the loss of DOC by photodegradation in our experiments may have been underestimated. Although spectral slopes in the 'before' exposure and dark treatments were not significantly different, significant increases in spectral slope were noted in both light treatments. There was a $15 \%$ increase in spectral slope in both PAR and TOTAL light treatments when compared to the dark controls (Figure 5(C)).

\section{Discussion}

\section{Evidence for seasonal photodegradation of DOC}

Our data, from both the field study and laboratory experiments, indicates that DOC in Pond 50 undergoes seasonal changes in optical and chemical characteristics and suggests that these changes are related to sunlight exposure. Although such temporal changes have been documented in deeper lakes (Morris and Hargreaves 1997; Osburn et al. 2001), they have rarely been reported for shallow wetlands like Pond 50 whose mean depth is $<1.0 \mathrm{~m}$. In fact, only one other study has reported seasonal changes in DOC optical characteristics in shallow mid-Western North American wetlands (Peterson et al. 2002).

When light, especially UVR, interacts with chromophoric constituents of aquatic DOC, a number of well documented changes occur. These include photobleaching (loss of colour) which causes changes in various DOC optical properties (absorption coefficients, spectral slope), decreases in the percentage of aromatic constituents and production of smaller, low molecular weight (LMW) carbon compounds (Chen et al. 1978; Morris and Hargreaves 1997; Moran et al. 2000; Osburn et al. 2001). All of these have been clearly demonstrated on a seasonal basis in Pond 50 by this study.

Absorbance scans from both years suggest that the chromophoric fraction, responsible for DOC absorbance, was being lost over time. In a study of Mid-western North American wetlands (Peterson et al. 2002), sites sampled late in the season (August to October) had a consistent pattern of lower UVB attenuation for a 
particular DOC concentration as compared to wetlands sampled earlier (March through July). The observed variability, reasoned the authors, suggested that UV absorptive properties of DOC changed seasonally (Peterson et al. 2002). Our study confirms that such seasonal changes do occur in prairie wetlands and in fact they can be significant - over the 2-year period seasonal losses of DOC specific absorptivity at $350 \mathrm{~nm}$ averaged greater than $30 \%$. This data also suggests that despite dramatic seasonal increases in DOC concentration, the capacity of DOC to absorb light was being lost faster than it could be replaced.

Seasonal changes in other optical properties in this pond were evident as well. In 1999, although DOC concentrations increased linearly with time from May through October (Figure 2(A)), fluorescence did not (Figure 3(B)). Initially, fluorescence increased rapidly with increasing DOC concentration until late June. If the portion of DOC responsible for fluorescence remained the same over time, one would expect that fluorescence would increase in the same fashion as DOC concentration. According to the DOC specific fluorescence this did not occur, indicating that constituents responsible for DOC fluorescence were being lost on a seasonal time scale. Sunlight mediated loss of DOC fluorescence has been documented elsewhere including ocean waters, where rates of fluorescence loss were much higher in surface waters than in deeper layers (Kouassi et al. 1990) and in leaf leachates (from Phragmites australis) where 70\% of DOC specific fluorescence was lost after exposure to artificial UVR for $72 \mathrm{~h}$ (Anesio et al. 1999).

The fluorescence changes reported from Pond 50, however, could also be due to a seasonal change in DOC source - in effect dilution of the bulk pool with autochthonously produced, less fluorescent DOC (Curtis and Schindler 1997). Because wetlands are typically shallow, highly productive water bodies, autochthonous DOC may markedly affect water colour (Peterson et al. 2002). According to Peterson et al. (2002), allochthonous sources might dominate during high water conditions of early spring and summer, while autochthonous sources, associated with late summer algal die-off, would predominate at later dates. The large numbers of macrophytes and high rates of attached and pelagic algal production in Pond 50 (Waiser 2001) likely all contribute to a dynamic pool of autochthonous DOC in this pond. Our data indicate, however, that the signal for this autochthonous DOC pool appears to be overwhelmed by the sheer amount of allochthonous DOC. Autochthonously produced DOC has a low C:N ratio, and is lower in aromaticity and less fluorescent than its allochthonous counterpart (McKnight et al. 1994, 2001). Average C:N ratios of DOC in Pond 50, however, were high (26:1 - Waiser 2001) and higher than would be expected based on a solely autochthonous source (McKnight et al. 1994). As well, hydrophobic acids comprised, on average, 50\% of the DOC (Waiser 2001) - much higher than the percentage for Antarctic lakes (18\% - McKnight et al. 1991) and Sky Pond, Colorado (16\% - McKnight et al. 1997) whose DOC was autochthonously derived. And finally, there was very little seasonal variation in the 450:500 fluorescence ratio $(1.54 \pm 0.01 \mathrm{SD} ; n=10-$ Waiser 2001) indicating not only that DOC is closer to the terrestrial signal of 1.4 as opposed to the autochthonous one (1.9-McKnight et al. 2001) but, more importantly, that DOC sources have remained constant. Although it could be argued 
that the changes in aromaticity documented here should cause a change in the fluorescence index, researchers have shown that DOC aromaticity may be altered by photobleaching without causing such a change (McKnight et al. 2001). Data presented here suggests, therefore, that seasonal changes in DOC fluorescence likely resulted from photodegradative processes and not from a predominance of autochthonously derived DOC later in the season.

Seasonal increases in spectral slope in both 1999 and 2000 were also indicative of solar radiation mediated changes in DOC optical properties. The spectral slope parameter provides a mechanism for estimating CDOM absorptivity across the solar spectrum and comparing optical properties over time and space (Moran et al. 2000). S data has therefore been used to track photochemical degradation of DOC (Morris and Hargreaves 1997; Vodacek et al. 1997; Moran et al. 2000) and the slope either increases (Vodacek et al. 1997; Moran et al. 2000; Whitehead et al. 2000) or decreases (Morris and Hargreaves 1997; Gao and Zepp 1998) in response to photodegradation. It is unclear why the differing results occur, although it may be related to DOC composition at differing wavelengths over which $S$ is calculated. Some authors also suggest that increases in $S$ are caused by a shift in the absorbance spectrum to lower wavelengths when higher molecular weight humic matter is broken down (Laurion et al. 2000; Whitehead et al. 2000). This explanation is probably the most applicable to Pond 50 as the tangential filtration and mass electrospray data both indicate seasonal declines in DOC molecular weight and size. Such photodegradative production of LMW compounds from higher molecular weight DOC has been observed in many other studies (Kieber et al. 1990; Wetzel et al. 1995; Bertilsson and Tranvik 2000).

$S$ values for Pond 50 are at the higher end of those observed as most freshwaters have slopes in the range of $0.010-0.025 \mathrm{~nm}^{-1}$ (Markager and Vincent 2000). There are no other reported $S$ values for wetlands. Higher $S$ values, however, are associated with LMW, autochthonous, or autochthonous-like DOC and/or a low percentage of humic acids (Markager and Vincent 2000; Whitehead et al. 2000). As well, spectral slopes also tend to be higher in the near surface layers where photodegradation is the greatest (Whitehead et al. 2000). Higher $S$ values observed here most likely reflect a combination of factors including the shallow nature of Pond 50 , seasonal decreases in DOC specific absorption coefficients, and increases in LMW carbon compounds and low percentages of humic acids (mean $=2.2 \%-$ Waiser 2001).

Because absorbance of UV light is linked to the presence of conjugated double bonds, and aromatic and phenolic moieties (Steinberg and Muenster 1985), a seasonal change in the percent aromaticity of DOC could be indicative of photodegradation. As well, a decline in percent carboxyl carbon might reflect photodecarboxylation of DOC ( $\mathrm{Li}$ et al. 1996). Our data clearly showed that seasonal changes in DOC optical properties were accompanied by decreases in DOC aromaticity and carboxylic constituents. Although many studies have linked changes in DOC optical properties with exposure to UVR, only one other study that we are aware of has correlated these with actual alteration of DOC chemical structure. In Lake Lacawac, Pennsylvania, 93-97\% of the DOC was isolated using reverse 
osmosis technology, lyophilized and subsequently analysed using ${ }^{13} \mathrm{C}$ NMR spectroscopy. This analysis revealed a $31 \%$ decrease in DOC aromaticity during the period April to September (Osburn et al. 2001). Our ${ }^{13} \mathrm{C}$ NMR data is not strictly comparable as we isolated only $\sim 50 \%$ of the DOC on XAD- 8 resins and subsequently analysed this fraction. Nonetheless, the two sets of data are similar in that both show seasonal declines in the percent aromaticity of DOC. In all likelihood, seasonal declines in specific absorbance and absorption coefficients noted in Pond 50 were a direct result of this loss of aromaticity. Our data also showed a decline in the percent carboxyl carbon (12\%) and decarboxylation to $\mathrm{CO}_{2}$ is thought to be a dominant photoreaction of aquatic humic material (Miller 1998).

The short-term photodegradation experiment, which documented an increase in spectral slope (inferring production of smaller DOC molecules) and DOC bleaching, confirmed the link between the in-pond changes in DOC optical characteristics we observed and sunlight. On average, however, there was a greater decline in absorption coefficients and increase in spectral slope in this experiment as compared to in situ results. One explanation was that seasonal changes in DOC optical characteristics and chemical structure in the pond included biological activity and wind-induced mixing, processes that were excluded during short-term incubations (Whitehead et al. 2000). Mid-continental climatic areas, like the prairies, are characteristically windy. For example, wind speed data from a meteorological station moored on Redberry Lake, about $150 \mathrm{~km}$ west of St. Denis, indicated that average maximum and minimum wind speeds were 28.9 and $6.7 \mathrm{~km} \mathrm{~h}^{-1}$, respectively (Arts et al. 2000). Due to its shallowness, Pond 50 never stratifies (see Results) and therefore, high wind events, characteristic of the region, stir up flocculent bottom sediments. Porewater DOC concentrations sometimes reach concentrations in excess of $140 \mathrm{mgl}^{-1}$ (T. Mayer, NWRI, unpublished data) and may be a source of fresh photoreactants, higher in molecular weight and absorptivity (Chin et al. 1998). The mixing of this unexposed with exposed DOC would tend to dampen the overall effect of sunlight on DOC optical and chemical characteristics. In the photodegradation experiment, however, there was a finite amount of DOC - no replacement from any sources - and the exposure containers were optically thin. The absolute amount of photobleaching and production of smaller DOC molecules, therefore, was greater than that observed in the pond. Our results differed from those of Osburn et al. (2001) who found that DOC molecular size in a bog water photodegradation experiment changed in a similar manner to those documented seasonally in Lake Lacawac. It may be that in some lakes, replenishment of fresh photoreactants is impeded by stratification which effectively isolates bottom sediments and porewater from overlying sunlit waters.

Also of interest in this study was the observation that DOC molecules were, on average, small and of low molecular weight even prior to any photodegradation (i.e. in spring). One factor influencing the size distribution of DOC molecules is the location of Pond 50 within a hydrologically closed basin. High molecular weight (HMW) DOC would probably only accrue to the basin during spring runoff, periods of overland flow associated with heavy rainfall events (Hinton et al. 1997; Molot and Dillon 1997) and possibly return of higher molecular weight DOC from sediment 
porewaters (Chin et al. 1998). In a study of wetland sediment porewater DOM, Chin et al. (1998) found that molecular weight of wetland DOM, expressed both as a weight- and number-average, was significantly higher in sediment porewater than in the overlying water. Limited sources of HMW DOC, combined with the fact that any DOC molecules entering the basin are essentially trapped, means that over longer time periods, photodegradation of DOC could change the molecular size spectrum more towards dominance by smaller molecules. This has been shown to be the case in hydrologically closed saline lakes of the northern prairie region (Waiser and Robarts 2000) and may be applicable to prairie wetlands as well.

\section{Between year differences}

DOC molecules were larger and exhibited higher specific absorption coefficients in spring 1999 than at a similar time in 2000. As well, based on the small differences in $S$ values, DOC molecules were more or less the same size in the fall of 1999 as compared to spring 2000. These data may reflect year to year differences in runoff. According to hydrologists studying Pond 50, runoff from the surrounding basin in spring 2000 was negligible. And although there was a $2 \mathrm{~cm}$ increase in water depth from October 1999 to May 2000, this only reflected the input of water by melting snow and ice on the pond surface (G. van der Kamp, NWRI, personal communication). Other studies have shown that when runoff events are dominated by flushing of soils, average molecular weight of DOC in receiving waters was higher due to the higher molecular weight of soil porewater DOC (Maurice et al. 2002). In 1999, therefore, runoff events probably brought higher molecular weight DOC having greater absorbance into the pond. But in spring 2000, with negligible runoff, DOC optical characteristics were more reflective of those seen the previous fall.

Although DOC optical properties remained similar from fall 1999 through spring 2000, DOC concentrations declined from 67.8 to $40.8 \mathrm{mg} \mathrm{l}^{-1}$ over the same time period. It seems unlikely that such a decline could be ascribed to decomposition as such activities would be limited by colder temperatures of fall and winter. The most likely explanation would be through dilution by snow meltwater. In 2000 , we know that meltwater runoff from the surrounding basin was negligible (see above). The most likely source of dilution water, therefore, would have been from snow which accumulated on top of the ice. Across the prairies, blowing snow readily accumulates on ice surfaces in depressional lowland waterbodies like Pond 50. The degree of dilution of DOC, however, will depend not only on the amount of snow meltwater added, but also the volume of water present in the pond.

Other year to year differences were apparent as well. In 1999, for example, from May until October as DOC concentration increased, DOC molecules continued to decrease in size as did the ability of DOC to absorb light. But in 2000, although DOC specific absorption coefficients and molecular size decreased initially, by midJuly no further declines were evident. There are a number of explanations. From the beginning of July until the end of August, DOC concentration increased by $23 \mathrm{mgl}^{-1}$, while at the same time the $1 \%$ penetration depth of UV-A and UV-B 
decreased by 3 and $1 \mathrm{~cm}$, respectively (Waiser 2001). Due to the increase in DOC concentration and decreased light penetration, a smaller fraction of the water column, and therefore less DOC would be available for photoreactions. Secondly, it may be that above DOC concentrations of about $70 \mathrm{mg} \mathrm{l}^{-1}$ (concentrations seen in mid-July), increases in constituents of DOC of higher absorbance simply balanced the rate at which colour was lost. But the addition of such elements would have to be of similar size in order for spectral slopes to remain more or less the same. And this is not consistent with our observation that as molecular size diminishes, so too does the ability of DOC to absorb light.

Finally, there may be some upper bound to the absolute amount of DOC which could be photodegraded over the time scale of this study. Many studies have demonstrated that only the light absorbing fraction of DOC is photoreactive while the remainder is resistant to photodegradation (Miller and Zepp 1995; Curtis 1998). Studies on loss rates of DOC in enclosures at the Experimental Lakes Area, Ontario, for example, revealed a more rapid loss rate for CDOM than for bulk DOC. This observation was consistent with two pools of DOC - a coloured component which was lost quickly and a low-colour component which was lost more slowly (Curtis and Schindler 1997).

In prairie wetlands, bulk DOC is likely comprised not only of DOC added from inpond sources and runoff events and labile DOC that cycles on fast time scales, but also a background of more recalcitrant DOC. According to our data, DOC in spring is comprised of a heterogeneous assortment of DOC molecules of varying molecular weights, which is, on average, higher in molecular weight, light absorbing capacity and aromaticity than DOC later in the season. This DOC probably reflects the character of fresh terrestrial material added during runoff from the basin. Soil derived DOC will not have experienced previous exposure to sunlight. And because of its higher aromaticity and absorbance capacity, it will likely be the most photoreactive part of the bulk DOC pool. Aromatic lignin-derived compounds are major constituents of terrestrial DOC and isotopically light (Benner et al. 1987). By mass balance, light-mediated removal of these lighter aromatic constituents, should shift the $\delta^{13} \mathrm{C}$ of bulk DOM to heavier signatures (Osburn et al. 2001). And in fact, our data shows this quite nicely with the $49 \%$ decline in aromatic constituents (from ${ }^{13} \mathrm{C}$ NMR) coinciding with a change from lighter to heavier $\delta^{13} \mathrm{C}$ DOC signatures. At the same time, seasonal losses of DOC specific absorbance and increases in spectral slope are also noted. Taken together, these data provide strong support for the selective degradation of terrestrial, aromatic components of pond DOC.

Assuming that input of terrestrial DOC provides more fresh photoreactants than does DOC originating from sediment porewater, the extent of these changes should be limited by the amount of fresh, photoreactive terrestrial material originating from the basin. Consequently, in years, like 2000 when there is little runoff (see above), less HMW photoreactive material (as indicated by higher spectral slopes in spring 2000) may be added to the bulk pool. Once this fresh material has been photodegraded, very little further transformation occurs. And this may explain the plateau observed in DOC absorption coefficients and molecular size in 2000. But further research, comparing soil, sediment and aquatic derived DOC is certainly required to test this hypothesis. 


\section{Factors influencing photodegradation}

A number of factors, including lack of stratification and concomitant mixing, likely influence DOC photodegradation in prairie wetlands. Rates of DOC photobleaching and loss have been shown to be higher in faster mixing systems as compared to their slower mixing counterparts (Whitehead et al. 2000). In slower mixing systems, photoreactions were restricted to the uppermost water layers while in faster mixing systems fresh photoreactants were constantly being brought to the surface layers where photoreactions occurred. Higher photodegradation rates for the entire water column were the result (Whitehead et al. 2000). Due to its shallow nature, Pond 50 never stratifies and mixing of the entire water column is expected especially during wind events. Such mixing probably brings fresh DOC from the sediments and sediment porewater (see above) to the surface layers where photodegradation can occur.

Light penetration and shallow depths are also factors which could influence DOC photodegradation in prairie wetlands. Chin et al. (1998) reasoned that in wetlands, higher DOC molecular weight in sediment porewaters as compared to overlying waters probably reflected substantial DOM photodegradation. In such systems, photodegradation would be favoured because surface area to volume ratios are large and sunlight could penetrate as far down as the benthic zone. Results from our photodegradation experiment clearly showed that PAR light was responsible for half the decline in the light absorbing capacity of DOC and almost $40 \%$ of the decrease in molecular size. Light penetration data for Pond 50 gathered as part of another study indicated that over the two year study period the $1 \%$ depth of PAR penetration averaged $1.3 \mathrm{~m}$ (Waiser 2001). Pond depth (taken at the center of the pond) varied from $71.5 \mathrm{~cm}$ in early May 1999 to $56 \mathrm{~cm}$ by mid-October while the decline for the same time period in 2000 was from 58 to $22.5 \mathrm{~cm}$. At all times of the year, therefore, PAR radiation capable of photodegrading DOC, was penetrating to the bottom throughout the pond. The average depth of UVR penetration, however, was not as great as PAR (mean $1 \% \mathrm{UV}-\mathrm{A}=13.0 \mathrm{~cm}$; mean $1 \% \mathrm{UV}-\mathrm{B}=4.0 \mathrm{~cm}-$ Waiser 2001). Photodegradation of DOC by UVR, therefore, was probably greatest at the shallow pond margins and in the upper few centimeters of open water. This observation is in agreement with other studies which suggest a smaller role for UVR in the photobleaching of DOC (Vahätälo et al. 2002). For example, in Lake Valkea-Kotinen, Finland, UV-B contributes only 5 and $1 \%$ to photobleaching at the surface and in the whole water column, respectively (Vahätälo et al. 2002).

\section{Conclusion}

It is clear that DOC in prairie wetlands becomes smaller in molecular weight, less aromatic and loses some of its capacity to absorb light as a result of seasonal exposure to sunlight. Our study indicates that DOC photodegradation is influenced by pond depth and continual mixing. It also underlines the importance of looking at seasonal changes in DOC optical characteristic and chemical composition and the factors 
affecting these processes. Had we only looked at DOCconcentration, we would have missed some important linkages. For example, other studies have shown that DOC in shallow wetlands, like Pond 50, is not as robust an indicator of UVB attenuation as it is in clearwater lakes (Arts et al. 2000; Peterson et al. 2002). Data presented here provide a reasonable explanation for this conclusion. Since attenuation of UVR by CDOM is partially ascribed to its aromatic constituents, seasonal losses mean that UVR penetration in these systems should be greater than predicted based on DOC concentration alone, which indeed it has shown to be. In deeper aquatic systems, this might not be so important, but prairie wetlands are not only shallow, they lose both water depth and volume seasonally - and they do not stratify. Refuge from potentially harmful UVR for many aquatic organisms, therefore, is scant. Taken together, all of these factors indicate that biota in prairie wetlands may not be as protected from harmful UVR as their high DOC concentrations would suggest. The significance of this conclusion to total wetland productivity remains to be assessed.

\section{Acknowledgements}

The authors thank Jennifer Holm and Vijay Tumber for technical assistance in the field and laboratory. We are also grateful for the assistance of the following people: Sue Abrams and Brock Chatson (NRC, Saskatoon $-{ }^{13} \mathrm{C}$ NMR), Kerry Peru (NWRI, Saskatoon - mass electrospray mass spectrometry) and Bill Donahue (University Alberta, Edmonton - DOC fluorescence). We also thank Lars Tranvik (Uppsala University, Uppsala, Sweden), Ruben Sommaruga (University of Innsbruck, Innsbruck, Austria), and two anonymous reviewers whose comments greatly improved the manuscript. This research was funded through Environment Canada's National Water Research Institute and an Institute for Wetland and Waterfowl Research grant to RDR.

\section{References}

Anesio A.M., Denward C.M.T., Tranvik L.J. and Graneli W. 1999. Decreased bacterial growth on vascular plant detritus due to photochemical modification. Aquat. Microb. Ecol. 17: 159-165.

Arts M.A., Robarts R.D., Kasai F., Waiser M.J., Tumber V., Plante A.L., Rai H. and de Lange H.J. 2000. The attenuation of ultraviolet radiation in high dissolved organic carbon waters of wetlands and lakes on the northern Great Plains. Limnol. Oceanogr. 45: 292-299.

Batt B.D., Anderson M.G., Anderson C.D. and Caswell F.D. 1989. The use of prairie potholes by North American ducks. In: van der Walk A.G. (Ed) Northern Prairie Wetlands. Iowa State University Press, Ames, pp. 204-227.

Benner R., Fogel M.L., Sprague E.K. and Hodson R.E. 1987. Depletion of ${ }^{13} \mathrm{C}$ in lignin and its implications for stable carbon isotope studies. Nature 329: 708-710.

Bertilsson S. and Tranvik L.J. 2000. Photochemical transformation of dissolved organic matter in lakes. Limnol. Oceanogr. 45: 753-762.

Chen Y., Khan U. and Schnitzer M. 1978. Ultraviolet radiation of dilute fulvic acid solutions. Soil Sci. Amer. J. 42: 292-296.

Chin Y.-P., Traina S.J., Swank C.R. and Backhus D. 1998. Abundance and properties of dissolved organic matter in pore waters of a freshwater wetland. Limnol. Oceanogr. 43: 1287-1296. 
Clair T.A. and Sayer B.G. 1997. Environmental variability in the reactivity of freshwater dissolved organic carbon to UV-B. Biogeochemistry 36: 89-97.

Curtis P.J. 1998. Climatic and hydrologic control of DOM concentration and quality in lakes. In: Hessen D.O. and Tranvik L.J. (eds) Aquatic Humic Substances: Ecology and Biogeochemistry. Springer, Berlin, pp. 93-105.

Curtis P.J. and Adams H.E. 1995. Dissolved organic matter quantity and quality from freshwater and saltwater lakes in Alberta. Biogeochemistry 30: 59-76.

Curtis P.J. and Schindler D.W. 1997. Hydrologic control of dissolved organic matter in low-order Precambrian Shield lakes. Biogeochemistry 36: 125-138.

Donahue W.F., Schindler D.W., Page S.J. and Stainton M.P. 1998. Acid-induced changes in DOC quality in an experimental whole-lake manipulation. Environ. Sci. Technol. 32: 2954-2960.

Environment Canada 1992. Analytical Methods Manual, Inland Waters Directorate, Water Quality Branch, Environment Canada.

Gao H. and Zepp R.G. 1998. Factors influencing photoreactions of dissolved organic matter in a coastal river of the south-eastern United States. Environ. Sci. Technol. 32: 2940-2946.

Hayashi M. 1996. Surface-subsurface transport cycle of chloride induced by wetland-focused groundwater recharge. Unpublished $\mathrm{PhD}$ Thesis, University of Waterloo, Ontario.

Hinton M.J., Schiff S.L. and English M.C. 1997. The significance of storms for the concentration and export of dissolved organic carbon from two Precambrian Shield catchments. Biogeochem. 37: 67-88.

Kieber D., Zhou X. and Mopper K. 1990. Formation of carbonyl compounds from UV-induced photodegradation of humic substances in natural waters: fate of riverine carbon in the sea. Limnol. Oceanogr. 35: 1503-1515.

Kouassi A.M., Zika R.G. and Plane J.M.C. 1990. Light-induced alteration of the photophysical properties of dissolved organic matter in seawater. Neth. J. Sea Res. 27: 33-41.

Laurion I., Ventura M., Catalan J., Psenner R. and Sommaruga R. 2000. Attenuation of ultraviolet radiation in mountain lakes: factors controlling the among- and within-lake variability. Limnol. Oceanogr. 45: 1274-1288.

Lean D.L. 1998. Attenuation of solar radiation in humic waters. In: Hessen D.O. and Tranvik L.J. (eds) Aquatic Humic Substances: Ecology and Biogeochemistry. Springer, Berlin, pp. 109-124.

Li J.W., Yu Z., Gao M., Zhang L., Cai X. and Chao F. 1996. Effect of ultraviolet radiation on the characteristics and trihalomethane formation potential of humic acid. Water Res. 30: 347-350.

Lindell M., Granéli W. and Tranvik L.J. 1995. Enhanced bacterial growth in response to photochemical transformation of dissolved organic matter. Limnol. Oceanogr. 40: 195-199.

Markager S. and Vincent W.F. 2000. Spectral light attenuation and the absorption of UV and blue light in natural waters. Limnol. Oceanogr. 45: 642-650.

Maurice P.A., Cabaniss S.E., Drummond J. and Ito E. 2002. Hydrogeochemical controls on the variations in chemical characteristics of natural organic matter at a small freshwater wetland. Chem. Geol. 187: 59-77.

McGaw B.A., Milne E. and Duncan G.J. 1988. A rapid method for the preparation of combustion samples for stable carbon isotope analysis by isotope ratio mass spectrometry. Biomed. Environ. Mass Spectrometry 16: 269-273.

McKnight D.M., Aiken D.R. and Smith R.L. 1991. Aquatic fulvic acids in microbially based ecosystems: Results from two desert lakes in Antarctica. Limnol. Oceanogr. 36: 998-1006.

McKnight D.M., Andrews E.D., Spaulding S.A. and Aiken G.R. 1994. Aquatic fulvic acids in Antarctic algal-rich ponds. Limnol. Oceanogr. 39: 1972-1979.

McKnight D.M., Harnish R.A., Wershaw R.L., Baron J.S. and Schiff S.L. 1997. Chemical characteristics of particulate, colloidal and dissolved organic matter in Loch Vale Watershed, Rocky Mountain National Park. Biogeochemistry 36: 99-124.

McKnight D.M., Boyer E.W., Westerhoff P.K., Doran P.T., Kulbe T. and Andersen D.T. 2001. Spectrofluorometric characterization of dissolved organic matter for indication of precursor organic material and aromaticity. Limnol. Oceanogr. 46: 38-48.

Miller W.L. 1998. Effects of UV radiation on aquatic humus: Photochemical principles and experimental considerations. In: Hessen D.O. and Tranvik L.J. (eds) Aquatic Humic Substances: Ecology and Biogeochemistry. Springer, Berlin, pp. 125-143. 
Miller W.L. and Zepp R.G. 1995. Photochemical production of dissolved organic carbon from terrestrial organic matter: significance to the oceanic organic carbon cycle. Geophys. Res. Lett. 22: 417-420.

Molot L.A. and Dillon P.J. 1997. Colour-mass balances and colour-dissolved organic carbon relationships in lakes and streams in central Ontario Can. J. Fish. Aquat. Sci. 54: 2789-2795.

Moran M.A., Sheldon W.M. and Zepp R.G. 2000. Carbon loss and optical property changes during longterm photochemical and biological degradation of estuarine dissolved organic matter. Limnol. Oceanogr. 45: 1254-1264.

Morris D.P. and Hargreaves B.R. 1997. The role of photodegradation of dissolved organic carbon in regulating transparency of three lakes on the Pocono Plateau. Limnol. Oceanogr. 42: 239-249.

Osburn C.L., Morris D.P., Thorn K.A. and Moeller R.E. 2001. Chemical and optical changes in freshwater dissolved organic matter exposed to solar radiation. Biogeochemistry 54: 251-278.

Peterson G.S., Johnson L.B., Axler R.P. and Diamond S.A. 2002. Assessment of the risk of solar ultraviolet radiation to amphibians. II. In situ characterization of exposure in amphibian habitats. Environ. Sci. Technol. 36: 2859-2865.

Schiff S.L., Aravena R., Trumbore S.E. and Dillon P.J. 1990. Dissolved organic carbon cycling in forested watersheds: a carbon isotope approach. Water. Resour. Res. 26: 2949-2957.

Schindler D.W. and Curtis P.J. 1997. The role of DOC in protecting freshwaters subjected to climatic warming and acidification from UV exposure. Biogeochemistry 36: 1-8.

Scully N.M., Lean D.R.S., McQueen D.J. and Cooper W.J. 1995. Photochemical formation of hydrogen peroxide in lakes: effects of dissolved organic carbon and ultraviolet radiation. Can. J. Fish. Aquat. Sci. 52: 2675-2682.

Steinberg C. and Muenster U. 1985. Geochemistry and ecological role of humic substances in lake water. In: Aiken G.R., McKnight D.M., Wershaw R.L. and MacCarthy P. (eds) Humic Substances: Soil, Sediment and Water - Geochemistry, Isolation and Characterization. Wiley, New York, pp. 105-145.

Su M., Stolte W.J. and van der Kamp G. 2000. Modeling Canadian prairie wetland hydrology using a semi-distributed streamflow model. Hydrol. Process. 14: 2405-2422.

Thurman E.M. and Malcolm R.L. 1981. Preparative isolation of aquatic humic substances. Environ. Sci. Technol. 15: 463-466.

Vähätalo A., Søndergaard M., Schlüter L. and Markager S. 1998. Impact of solar radiation on the decomposition of detrital leaves of eelgrass Zostera marina. Mar. Ecol. Progr. Ser. 170: 107-117.

Vähätalo A., Salonen K., Saski E. and Salkinoja-Salonen M.S. 2002. Bleaching of color of kraft pulp mill effluents and natural organic matter in lakes. Can. J. Fish. Aquat. Sci. 59: 808-818.

Vodacek A., Blough N.V., de Grandpre M.D. and Nelson R.K. 1997. Seasonal variation of CDOM and DOC in the Middle Atlantic Bight: Terrestrial inputs and photooxidation. Limnol. Oceanogr. 42: 674-686.

Voyksner R.D. 1994. Atmospheric pressure ionization LC/MS: new solutions for environmental analysis. Environ. Sci. Technol. 28: 118A-127A.

Waiser M.J. 2001. The effect of solar radiation on the microbial ecology and biogeochemistry of prairie wetlands. Unpublished PhD Thesis, Napier University, Edinburgh, Scotland.

Waiser M.J. and Robarts R.D. 2000. Changes in composition and reactivity of allochthonous DOM in a prairie saline lake Limnol. Oceanogr. 40: 566-574.

Wetzel R.G., Hatcher P.G. and Bianchi T.S. 1995. Natural photolysis by ultraviolet radiation of recalcitrant dissolved organic matter to simple substrates for rapid bacterial metabolism. Limnol. Oceanogr. 40: 1369-1380.

Whitehead R.F., de Mora D., Demers S., Gosselin M., Montfort P. and Mostajir B. 2000. Interactions of UV-B radiation, mixing and biological activity on photobleaching of natural CDOM: a mesocosm study. Limnol. Oceanogr. 45: 278-291

Woo M.-K. and Rowsell R.D. 1993. Hydrology of a prairie slough. J. Hydrol. 146: 175-200. 